\title{
PANORAMA DAS PESQUISAS SOBRE ABORDAGEM CTS NO ENSINO DE QUÍMICA NO ENPEC
}

\author{
OVERVIEW OF RESEARCH ON STS APPROACHES IN CHEMISTRY TEACHING AT \\ ENPEC
}

\author{
Sandra Cristina da Silva ${ }^{1}$, Pedro Miranda Junior ${ }^{2}$ \\ Recebido: dezembro/2019 Aprovado: outubro/2021
}

\begin{abstract}
Resumo: Este trabalho tem por objetivo analisar as publicações realizadas no Encontro Nacional de Pesquisa em Educação em Ciências (ENPEC) sobre abordagem CTS (Ciência, Tecnologia e Sociedade) no Ensino de Química. Para isso realizou-se uma pesquisa qualitativa, de caráter bibliográfico, para selecionar artigos publicados no ENPEC durante o período de 2011 a 2019, contendo palavras-chave "ensino de química" e/ou "química". Os 46 artigos selecionados foram analisados a partir dos pressupostos da análise de conteúdo de Bardin por meio das seguintes categorias de análise: palavras-chave; natureza do trabalho; público alvo; temas sociais geradores; referenciais teóricos. A partir da análise dos dados verificou-se que CTS, CTSA e Ensino de Química foram palavras-chave de maior relevância na área de pesquisa. Os trabalhos são na maioria de natureza empírica, envolvendo uma diversidade de temas socioambientais desenvolvidos principalmente com estudantes do Ensino Médio e do Ensino Superior. A análise indicou Wildson L. P. Santos como o principal referencial teórico citado nos trabalhos analisados. A pesquisa mostrou que, apesar de uma pequena tendência de aumento de publicações CTS no Ensino de Química nas edições do ENPEC, faz-se necessária reflexão sobre a inserção da abordagem CTS em sala de aula com foco na interdisciplinaridade.
\end{abstract}

Palavras-chave: CTS, Ensino de Química, ENPEC.

Abstract: This work aims to analyze the works published at the National Meeting of Research in Science Education (ENPEC) about STS (Science, Technology and Society) approach in Chemistry Teaching. For this, a qualitative bibliographical research was carried out to select articles published in ENPEC during the period from 2011 to 2019, containing keywords "teaching of chemistry" and/or "chemistry". The 46 selected articles were analyzed based on Bardin's content analysis assumptions through the following analysis categories: keywords; nature of work; target audience; generative social themes; theoretical frameworks. From the data analysis, it was found that STS, ASTS and Chemistry Teaching were the most relevant keywords in the research area. The works are mostly empirical in nature, involving a variety of socio-environmental themes developed mainly with High School and Higher Education students. This analysis indicated Wildson L. P. Santos as the main theoretical reference cited in the collected works. The research shows that despite a small upward trend in STS publications in Chemistry Teaching in ENPEC editions, thinking about the insertion of the STS approach in the classroom with focus on interdisciplinarity is necessary.

Keywords: STS, teaching of chemistry, ENPEC.

\section{Introdução}

A educação no Brasil, segundo a legislação, permeia diversos campos, desde espaços formativos como a escola e outros como a vida familiar, o trabalho e a vida em sociedade. Esses

https://orcid.org/0000-0003-2629-8178- Licencianda em Química pelo Instituto Federal de Educação, Ciência e Tecnologia de São Paulo (IFSP), câmpus São Paulo, SP, BR. Rua Pedro Vicente, 625, CEP 01109-010, São Paulo, SP, BR. E-mail: scsilva.pj@gmail.com

2 (D) https://orcid.org/0000-0002-4830-0550 - Doutor em Química pela Universidade de São Paulo (USP). Docente no Instituto Federal de Educação, Ciência e Tecnologia de São Paulo (IFSP), câmpus São Paulo, SP, BR. Rua Pedro Vicente, 625, CEP 01109-010, São Paulo, SP, BR. E-mail: pedro.mjr@ifsp.edu.br 
espaços contribuem para a aprendizagem e formação de um cidadão consciente e crítico que respeita os direitos humanos e o meio ambiente, dentre outros aspectos. A abrangência da educação é apresentada no artigo 1ㅇ da LDB - Lei de Diretrizes e Bases da Educação Nacional: "A educação abrange os processos formativos que se desenvolvem na vida familiar, na convivência humana, no trabalho, nas instituições de ensino e pesquisa, nos movimentos sociais e organizações da sociedade civil e nas manifestações culturais" (BRASIL, 1996).

Os aspectos de formação cidadã também são encontrados na BNCC - Base Nacional Comum Curricular, que prevê o desenvolvimento de 10 competências gerais da Educação Básica que visam fortalecer os direitos de aprendizagem e desenvolvimento dos estudantes, propondo a articulação na construção de conhecimentos, no desenvolvimento de habilidades e na formação de atitudes e valores. Esses aspectos são descritos na sétima competência da BNCC:

Argumentar com base em fatos, dados e informações confiáveis, para formular, negociar e defender ideias, pontos de vista e decisões comuns que respeitem e promovam os direitos humanos, a consciência socioambiental e o consumo responsável em âmbito local, regional e global, com posicionamento ético em relação ao cuidado de si mesmo, dos outros e do planeta (BRASIL, 2017, p. 9).

O Ensino de Química deve englobar tais processos formativos, principalmente porque a Ciência está no cotidiano dos estudantes/cidadãos que vivem num ambiente rodeado por elementos e substâncias químicas, recursos tecnológicos e uma linguagem que, além de específica, advém de conhecimentos químicos. Alguns produtos obtidos graças ao avanço da tecnologia são conhecidos pelos estudantes, porém como vivemos em uma sociedade desigual nem todos têm acesso a eles, tais como: medicamentos, perfumes, xampus, combustíveis, equipamentos eletrônicos, alimentos e embalagens. Algumas substâncias vitais para a manutenção da vida humana foram nomeadas há muito tempo pela Ciência, por exemplo, o oxigênio e e a água. Outras substâncias como proteínas, carboidratos, enzimas e vitaminas, apesar de serem substâncias essenciais nos processos biológicos, são pouco compreendidas pelos estudantes (LUCA, 2001).

É fato que a Ciência e a Tecnologia influenciam e modificam a nossa interpretação do mundo, a forma como pensamos, nos comportamos, nossos desejos individuais e a nossa cultura (PIZZATO, 2013). Esse fato evidencia a relevância de um ensino que vá além da aprendizagem dos saberes científicos, mas que considere as implicações do conhecimento em relação aos aspectos tecnológicos, sociais, ambientais, culturais e históricos, vivenciados na sociedade. Porém, no modelo pedagógico ainda utilizado em sala de aula, tais conhecimentos tornam-se dogmas ao invés de aprendizagem, fato este evidenciado por Schnetzler e Aragão (1995) quando trazem a seguinte reflexão sobre o ensino:

Uma prática de ensino encaminhada quase exclusivamente para a retenção, por parte do aluno, de enormes quantidades de informações passivas, com o propósito de que essas sejam memorizadas, evocadas e devolvidas nos mesmos termos em que foram apresentadas - na hora dos exames, através de provas, testes, exercícios mecânicos repetitivos - expressa muito bem uma concepção de ensino-aprendizagem correspondente ao modelo de transmissão-recepção (tradicional) (SCHNETZLER; ARAGÃO,1995, p. 27). 
Abarcar as especificidades da química no Ensino de Ciências se faz necessário para que o sujeito possa interagir de maneira mais completa, responsável e consciente com o meio em que vive e que se transforma constantemente. Para isso é importante pensar em um Ensino de Química contextualizado que possibilite uma aprendizagem significativa, assim como Santos e Schnetzler (2003) afirmam:

É necessário que os cidadãos conheçam como utilizar as substâncias no seu dia a dia, bem como se posicionarem criticamente com relação aos efeitos ambientais da utilização da química e quanto às decisões referentes aos investimentos nessa área, a fim de buscar soluções para os problemas sociais que podem ser resolvidos com a ajuda do seu desenvolvimento (SANTOS; SCHNETZLER, 2003, p.47).

A importância do conhecimento químico para a formação cidadã também é discutida e evidenciada em outros documentos oficiais, como o PCN - Parâmetros Curriculares Nacionais: "Os conhecimentos difundidos no ensino da Química permitem a construção de uma visão de mundo mais articulada e menos fragmentada, contribuindo para que o indivíduo se veja como participante de um mundo em constante transformação" (BRASIL, 2009, p. 32).

A escola tem um papel importante na formação cidadã, tendo por função contribuir para promoção do exercício da cidadania, desenvolvimento do pensamento crítico e apropriação de conhecimentos relacionados às particularidades de cada disciplina. Sabendo que a química está presente em nosso cotidiano de diversas maneiras, se faz necessário praticar um Ensino de Ciências por meio do uso de diferentes abordagens, visando minimizar o distanciamento entre as especificidades da disciplina e o cotidiano dos alunos.

A preocupação por parte dos educadores em desenvolver estratégias pedagógicas que sejam mais significativas aos educandos é um desafio constante. Diante dessa perspectiva surge a abordagem CTS (Ciência, Tecnologia e Sociedade) que permite essa conexão devido a sua pluralidade. Segundo Santos e Mortimer (2002), tal abordagem tem como objetivo central preparar os alunos para o exercício da cidadania e caracteriza-se por um ensino de conteúdos científicos no seu contexto social, ou seja, propõe a transposição dos conteúdos de maneira contextualizada e significativa para o aluno, objetivando a melhor compreensão da disciplina de química, interligando as relações existentes entre ciência, tecnologia e as consequências para a sociedade e o ambiente.

O movimento CTS surgiu na década 1960 em alguns países do hemisfério norte, sob a influência de correntes filosóficas advindas do período pós-segunda guerra mundial, momento em que a atmosfera eufórica surgida por conta dos avanços científicos do período tornou-se um alerta frente a uma série de desastres ambientais ocorridos a partir de 1950. Um dos nomes ascendentes que impulsionou o movimento CTS foi o da jornalista Rachel Carson que, em 1962, lançou o livro "Primavera Silenciosa", um clássico do movimento ambientalista que trouxe muitas inquietações para o mundo, estimulando a formação de muitas organizações com o intuito de discutir a crise ambiental da época e futura, como relata Pizzato (2013, p. 8):

O agravamento dos problemas ambientais pós-guerra também fez surgir um sentimento de que o modelo linear de desenvolvimento era falho, e uma consciência crítica a respeito da ciência, da tecnologia e de suas consequências. Associadas a isso, a tomada de consciência 
de muitos intelectuais com relação às questões éticas, à qualidade de vida da sociedade industrializada e à necessidade da participação popular nas decisões públicas propiciaram as condições para o surgimento do chamado movimento CTS.

No Brasil, a repercussão da abordagem CTS foi lenta. Apesar de haver uma preocupação de se implantar o CTS no currículo, somente no final da década de 1990 é que o movimento ganhou força e como consequência materiais didáticos com essa abordagem começaram a surgir no mercado editorial (SANTOS et al., 2010).

Segundo Santos et al. (2010), o currículo CTS deve ser pensado de maneira a promover a educação científica e tecnológica dos cidadãos de maneira consciente, crítica e participativa na resolução dos problemas atuais decorrentes do próprio uso das tecnologias e dos conhecimentos científicos. Entretanto, para que os alunos desenvolvam esta capacidade de tomada de decisão é necessário o desenvolvimento, primeiramente, da capacidade de argumentação, pois para resolverem um dado problema ou se posicionarem sobre um determinado fato, eles devem expor de forma clara e precisa suas opiniões. Tais aspectos demonstram o quanto essa abordagem, apesar de ser desafiadora, é necessária para a Educação.

Ainda no contexto da educação científica, Strieder e Kawamura (2017) para fomentar a discussão sobre a polissemia do campo CTS na educação científica, a partir de um trabalho teórico-empírico, desenvolveram uma matriz de referência para identificar diferentes dimensões da proposta CTS em práticas escolares. Neste trabalho as autoras descreveram duas dimensões: Parâmetros da Educação CTS e Propósitos da Educação CTS. Os Parâmetros compreendem as diferentes formas de perceber a ciência, a tecnologia e a sociedade e são formados por três elementos: (i) racionalidade científica; (ii) desenvolvimento tecnológico; (iii) prática social. Já os Propósitos são organizados em três grupos que objetivam a educação científica para contribuir para o desenvolvimento de: (i) percepções; (ii) questionamentos; e (iii) compromissos sociais.

Segundo as autoras, a proposta da matriz não objetiva simplesmente classificar trabalhos CTS, indo além disso, ao possibilitar reconhecimento das diferentes dimensões da Educação CTS praticadas no Ensino de Ciências no contexto brasileiro, como também das dimensões que possam ser contempladas em pesquisas futuras sobre a abordagem CTS.

Estudos sobre as potencialidades do uso da abordagem CTS ou CTSA (Ciência, Tecnologia, Sociedade e Ambiente) no Ensino de Ciências estão cada vez mais difundidos no meio acadêmico, pois são pesquisas desenvolvidas por professores, estudantes e pesquisadores vinculados a diferentes instituições de ensino do país em diversos tipos de programas de pesquisa, como por exemplo, programas de pós-graduação na área de Ensino de Ciências e o PIBID (Programa Institucional de Bolsas de Iniciação à Docência) vinculado aos cursos de formação inicial de professores.

Para compreender como essas abordagens são discutidas por esses autores nos diferentes tipos de produção - artigos de periódicos, trabalhos em eventos científicos, dissertações de mestrado, e teses de doutorado - trabalhos de revisão bibliográfica ou de estado 
da arte tornaram-se frequentes e relevantes para compreender o grande volume de trabalhos desenvolvidos com esta temática no território nacional.

Neste cenário destacamos os trabalhos de revisão bibliográfica de Freitas e Ghedin (2015), Locatelli et al. (2015), Bouzon et al. (2018), Castro et al. (2019) e Sousa et al. (2019). No estudo de Bouzon et al. (2018), os autores realizaram uma revisão bibliográfica sobre o Ensino de Química com enfoque CTS desenvolvido no Brasil com base no mapeamento de palavras-chave, autores e obras mais citadas a partir da análise de 41 artigos selecionados em 31 periódicos nacionais, publicados no período de 1996 a 2016. No artigo de Locatelli et al. (2015), os autores analisaram, no período de 2010 a 2014, 66 trabalhos - resumos, resumos expandidos e artigos completos - relacionados às abordagens CTS e CTSA publicados nas atas dos seguintes eventos nacionais: Reuniões Anuais da Sociedade Brasileira de Química (RASBQ); Encontros Nacionais de Ensino de Química (ENEQ); Encontros de Debates Sobre o Ensino de Química (EDEQ); e Encontros Nacionais de Pesquisa em Educação em Ciências (ENPEC).

O trabalho publicado por Castro et al. (2019) também analisou trabalhos sobre a abordagem CTS e o Ensino de Química, porém utilizou como fonte de dados as atas do ENEQ (Encontro Nacional em Ensino de Química) no período de 2012 a 2018 no intuito de levantar as atuais tendências desta abordagem no Ensino de Química. No trabalho de revisão bibliográfica, Sousa et al. (2019) descrevem sobre contribuições referentes às relações CTS/CTSA e o Ensino de Química, tendo com fonte de dados 25 artigos acadêmicos selecionados no portal de periódicos da Capes durante o período de 2003 a 2017.

Para analisar a linha de pesquisa CTS, o público investigado, a implementação da abordagem da CTS em sala de aula, dentre outros aspectos, Freitas e Ghedin (2015) apresentam em seu estudo uma análise comparativa temporal considerando 13 produções sobre estado da arte em CTS, publicadas no período de 2008 a 2013, e 21 artigos selecionados em quatro periódicos nacionais, publicados no período de 2009 a 2013.

Mediante a importância de ampliar ainda mais as discussões sobre a abordagem CTS no Ensino de Química, buscou-se realizar um panorama das publicações com este tema de pesquisa, por meio de um levantamento dos artigos completos publicados nas atas das edições do ENPEC (Encontro Nacional de Pesquisa em Educação em Ciências) no período de 2011 a 2019, para compreender de que forma pesquisadores e professores estão estudando e incluindo a abordagem CTS em suas rotinas pedagógicas, buscando assim evidenciar aspectos que caracterizam o uso desta abordagem no Ensino de Química.

\section{Metodologia}

O presente trabalho, desenvolvido em uma abordagem qualitativa, é de caráter bibliográfico, tipo de pesquisa "desenvolvida com base em material já elaborado, constituído principalmente de livros e artigos científicos" (GIL, 2017, p. 44). Os artigos selecionados foram analisados com base nos pressupostos da Análise de Conteúdo de Bardin (2011), técnica de análise que tem como propósito descrever os conteúdos coletados de maneira sistematizada. 
Para compreender como a abordagem CTS no Ensino de Química vem sendo estudada e empregada em sala de aula, buscou-se analisar trabalhos de pesquisadores e professores no contexto nacional. Para tal, escolheu-se analisar as atas publicadas nos últimos cinco ENPEC, relativos às edições de 2011, 2013, 2015, 2017 e 2019. O ENPEC, além de ser um evento importante para divulgação das pesquisas desenvolvidas na área de Ensino de Ciências, apresenta uma linha temática direcionada para publicações relacionadas às abordagens CTS/CTSA.

O ENPEC é um evento nacional que consiste em encontros bienais, abertos a todos os pesquisadores e professores que realizam investigações nas áreas de Ensino de Física, Química, Biologia, Matemática, Geociências, Educação para a Saúde, Educação Ambiental e áreas afins. Desde 1997, o evento é promovido pela Associação Brasileira de Pesquisa em Educação em Ciências - ABRAPEC e, em 2019, na cidade de Natal (RN) ocorreu a sua 12a edição. Devido a sua representatividade no Ensino de Ciências, o ENPEC recebe diversos trabalhos de pesquisa, de natureza empírica ou teórica, que são organizados em diversas áreas; por exemplo, o ENPEC 2019 contou com 15 linhas temáticas, relacionadas no Quadro 1.

Quadro 1 - Linhas temáticas do XII ENPEC .

\begin{tabular}{|l|}
\hline \multicolumn{1}{|c|}{ Linhas Temáticas } \\
\hline 1 - Ensino e aprendizagem de conceitos e processos científicos \\
\hline 2 - Formação de Professores \\
\hline 3 - História, Filosofia e Sociologia da Ciência \\
\hline 4 - Educação em espaços não formais e divulgação científica \\
\hline 5 - Tecnologias da informação e comunicação na Educação em Ciências \\
\hline 6 - Educação Ambiental \\
\hline 7 - Educação em Saúde \\
\hline 8 - Linguagens e Discurso \\
\hline 9 - Alfabetização científica e tecnológica, abordagens CTS/CTSA \\
\hline 10 - Currículos \\
\hline 11 - Avaliação e Educação em Ciências \\
\hline 12 - Diversidade, multiculturalismo, interculturalidade \\
\hline 13 - Processos, recursos e materiais educativos \\
\hline 14 - Políticas educacionais \\
\hline 15 - Questões teóricas e metodológicas da pesquisa \\
\hline
\end{tabular}

Foram selecionados para análise somente os artigos da linha temática "Alfabetização científica e tecnológica, abordagens CTS/CTSA" que tinham como palavra-chave "química" ou "ensino de química" e discutiam especificamente as abordagens CTS e/ou CTSA, resultando em um corpus de 46 artigos completos, publicados nas atas da 8a a 12a edições do ENPEC, durante o período de 2011 a 2019.

Seguindo os procedimentos de análise de conteúdo, a análise iniciou-se com a leitura flutuante dos 46 artigos selecionados e, a partir desta leitura, foram formuladas hipóteses e

${ }^{3}$ XII ENPEC: http://www.abrapecnet.org.br/enpec/xii-enpec/txt/3 
construídos indicadores que serviram de ferramentas importantes para posterior interpretação dos resultados. No Quadro 2 são apresentadas as categorias e seus descritores propostas para análise dos artigos selecionados.

Quadro 2-Descrição das Categorias de Análise

\begin{tabular}{|l|l|}
\hline \multicolumn{1}{|c|}{ CATEGORIA } & \multicolumn{1}{c|}{ DESCRIÇÃO } \\
\hline Palavras-Chave & $\begin{array}{l}\text { Possibilita identificar principais ideias e temas abordados na } \\
\text { pesquisa. }\end{array}$ \\
\hline Natureza do Trabalho & Analisa se o trabalho é de natureza teórica ou empírica. \\
\hline Público Alvo & Identifica o público alvo abrangido pelas pesquisas CTS analisadas. \\
\hline Temas Sociais Geradores & $\begin{array}{l}\text { Apresenta os principais temas geradores utilizados para o } \\
\text { desenvolvimento da abordagem CTS em sala de aula. }\end{array}$ \\
\hline Referenciais Teóricos & $\begin{array}{l}\text { Relaciona os principais autores e obras de utilizados como } \\
\text { referenciais teóricos. }\end{array}$ \\
\hline
\end{tabular}

Fonte: os autores

\section{Resultados e Discussão}

Primeiramente realizou-se um levantamento dos trabalhos publicados nas atas da 8 a a 12a edições do ENPEC, durante os anos de 2011 a 2019, a fim de traçar um panorama geral do Evento durante o período considerado. Na Tabela 1 são apresentados, para cada edição do ENPEC, o número total de trabalhos publicados, o número de trabalhos agrupados na linha temática "Alfabetização científica e tecnológica, abordagens CTS/CTSA" e o número de trabalhos selecionados para análise.

Tabela 1 - Panorama de trabalhos do ENPEC nas edições de 2011 a 2019.

\begin{tabular}{|l|l|c|c|c|}
\hline Edição/Ano & Local do Evento & $\begin{array}{c}\text { Total de } \\
\text { Trabalhos }\end{array}$ & $\begin{array}{c}\text { Trabalhos da } \\
\text { Linha Temática }\end{array}$ & $\begin{array}{c}\text { Trabalhos } \\
\text { Selecionados }\end{array}$ \\
\hline VIII - 2011 & Campinas - SP & 1235 & 72 & 11 \\
\hline IX - 2013 & Águas de Lindoia - SP & 1060 & 64 & 5 \\
\hline X- 2015 & Águas de Lindoia- SP & 1272 & 64 & 6 \\
\hline XI - 2017 & Florianópolis - SC & 1335 & 110 & 13 \\
\hline XII - 2019 & Natal - RN & 1254 & 90 & 11 \\
\hline
\end{tabular}

Fonte: os autores

Analisando a Tabela 1, mais especificamente a coluna "total de trabalhos", percebe-se que não há um aumento relativo, mas sim uma oscilação, de trabalhos publicados nas atas do ENPEC. Ao comparar a quantidade de trabalhos aceitos em bienais consecutivas, observam-se variações positivas e negativas. Para as edições de 2011 e 2013, nota-se um decréscimo de 14\% 
de uma bienal para outra. Fazendo o mesmo comparativo nos anos de 2013 e 2015 o volume de trabalhos publicados aumenta em 20\%. Já na bienal seguinte, que corresponde ao ano de 2017, o total de trabalhos aceitos é $5 \%$ maior quando comparado à edição anterior. E na última bienal considerada, a de 2019 , tem-se um decréscimo de $6 \%$ de trabalhos publicados em relação ao ano de 2017.

Em relação aos quantitativos de trabalhos da linha temática e de trabalhos selecionados, observa-se uma oscilação com ligeira tendência de aumento no decorrer do período considerado, porém o número de publicações mais expressivo aconteceu na edição de 2017, evento que ocorreu na cidade de Florianópolis (SC).

\section{Categoria - Palavras-chave}

As palavras-chaves são um bom indicativo da linha de pesquisa do trabalho consultado, indicam ao leitor temas/assuntos a serem abordados no referido trabalho e também são utilizadas como fontes em mecanismos de busca de trabalhos relacionados a um determinado tema de pesquisa.

Nos 46 artigos selecionados encontrou-se um total de 166 palavras-chave; para aquelas com duas ou mais citações construiu-se uma nuvem de palavras representada na Figura 1, utilizando o aplicativo online WordArt.com. As palavras mais citadas na figura aparecem com letras maiores, destacando temas abordados com maior frequência.

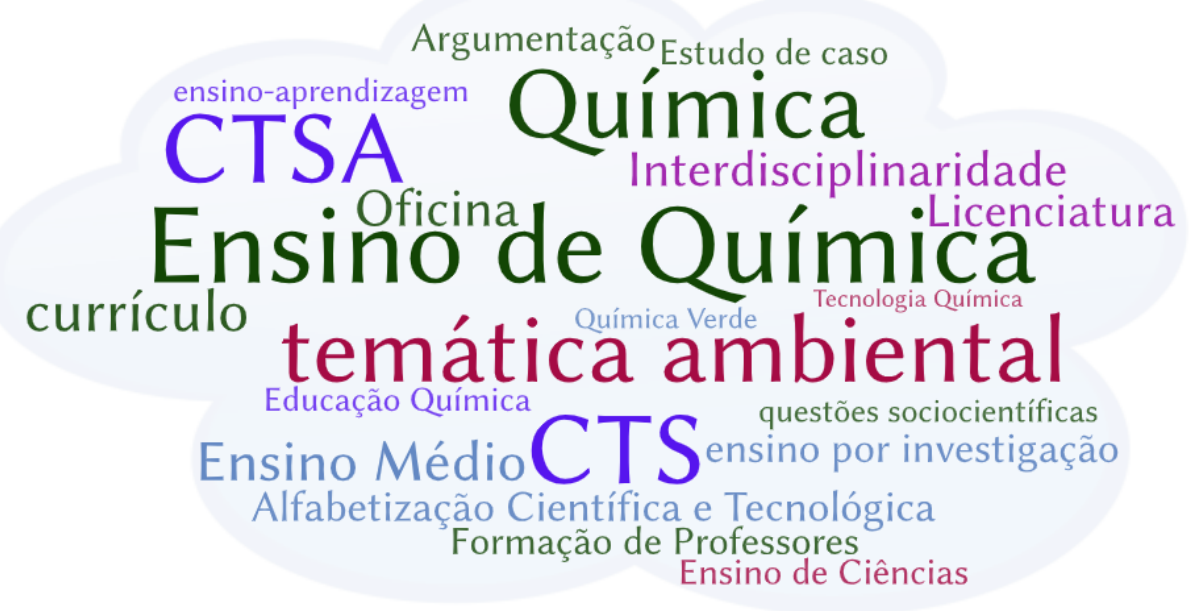

Figura 1 - Nuvem de palavras com as palavras-chaves dos artigos selecionados

Fonte: os autores

Na Figura 1, observamos que as palavras-chave com maior destaque foram CTS, CTSA e Ensino de Química, dado também evidenciado no trabalho de revisão de Bouzon et al. (2018), que indica CTS e Ensino de Química como as duas palavras-chave que tiveram maior relevância dentro da área de pesquisa. Os referidos autores, a partir do estudo de uma rede social construída com palavras-chave com base na Teoria de Grafos, destacam que as palavras CTS e Ensino de Química possuem elevadas medidas de centralidade, o que indica maior poder de comunicação destas palavras com as demais representadas na rede social. 
Em relação às demais palavras-chave mais citadas na Figura 1, destacam-se também as palavras-chave: Química, temática ambiental, Ensino Médio, alfabetização científica e tecnológica e interdisciplinaridade. Essas palavras possuem uma relação direta com as abordagens CTS/CTSA, já que o Ensino de Química, por meio de temáticas ambientais com vistas à interdisciplinaridade, é potencializado por essas abordagens, contribuindo para uma educação mais humanizada para promoção da alfabetização científica e tecnológica de estudantes do Ensino Médio, cidadãos que fazem uso do conhecimento químico para embasar suas argumentações diante de debates sobre questões relacionadas à Ciência, Tecnologia e Sociedade.

\section{Categoria - Natureza do Trabalho}

Dentro da categoria Natureza do trabalho, os trabalhos foram classificados como de natureza teórica ou empírica. Consideramos como pesquisa teórica aquela "dedicada a reconstruir teoria, conceitos, ideias, ideologias, polêmicas, tendo em vista, em termos imediatos, aprimorar fundamentos teóricos" (DEMO, 2000, p. 20); incluímos também nessa categoria os trabalhos de revisão bibliográfica. Por exemplo, o artigo "Reflexões e desafios acerca da abordagem Ciência, Tecnologia, Sociedade e Ambiente na Educação em Ciências/Química na formação do cidadão", foi classificado como trabalho de natureza teórica, pois trata de um trabalho de revisão de artigos científicos publicados nas atas do ENPEC de 2015, que traz a seguinte reflexão sobre a proposta do trabalho:

No que diz respeito às concepções convergentes do enfoque CTSA identificadas nas produções estudadas, essas acordavam em relação à importância da abordagem do conteúdo de forma integrada e desenvolvimento de temas sociais, relacionados com o cotidiano do educando. Santos e Schnetzler (2003) esclarecem que os conteúdos dos cursos CTS implicam na inclusão de temas sociais, que objetivam a contextualização do conteúdo e permitem o desenvolvimento das habilidades essenciais do cidadão (SOUZA, et al., 2015, p.7).

Já a pesquisa empírica é aquela que "dedica ao tratamento da face empírica e fatual da realidade; produz e analisa dados, procedendo sempre pela via do controle empírico e fatual" (DEMO 2000, p. 21). Dentre os trabalhos empíricos encontrados destacam-se aqueles que analisam sequências didáticas (SD) com as mais diversas temáticas, utilizando diferentes estratégias didáticas de ensino, tais como atividades investigativas, jogos, entre outras. Nesta categoria trazemos como exemplo o artigo "Contextualizando conceitos de reutilização e reciclagem como motivação para compreensão da ciência no âmbito social na Educação de Jovens e Adultos", uma pesquisa empírica que retrata a reutilização de materiais com uma turma de Educação de Jovens e Adultos (EJA); os autores relatam que o desenvolvimento dos conceitos químicos partiu do tema social gerador escolhido pelos próprios alunos que foi sobre "animais abandonados". A turma construiu casas para os animais abandonados da cidade, reutilizando materiais do cotidiano como latas de tintas, camisetas, papelão, entre outros. Sobre o desenvolvimento da SD os autores trazem a seguinte consideração:

Sobre o aspecto social envolvido com os animais abandonados, destacaram a importância de políticas públicas acerca de seu controle na cidade, bem como maus tratos desses 
animais em bairros carentes na cidade. O debate foi muito produtivo e foi possível observar um real envolvimento da turma com a relação da ciência no seu dia a dia e acima de tudo o impacto que a falta do conhecimento desta pode causar. (OLIVEIRA; SALGADO, 2017, p.7)

A maioria dos 46 trabalhos analisados é de natureza empírica; $75 \%$ dos trabalhos foram classificados como empíricos. Isso pode estar atrelado ao fato de que boa parte dos trabalhos analisados envolve ações com alunos da Educação Básica, em que a maioria abrange o desenvolvimento e a análise de sequências didáticas. A expressiva quantidade de trabalhos empíricos também foi reportada por Castro et al. (2019) ao analisarem as atas do ENEQ (Encontro Nacional de Ensino de Química), um importante evento nacional da área de Ensino de Química. Os referidos autores destacam que as produções empíricas analisadas indicam que a abordagem CTS está cada vez mais presente em atividades desenvolvidas em sala de aula.

\section{Categoria - Público Alvo}

Nesta categoria buscou-se identificar o público alvo abrangido pelas pesquisas CTS analisadas. De acordo com os dados obtidos, representados na Figura 2, nota-se que a maioria das pesquisas envolve estudantes do Ensino Médio (EM) e do Ensino Superior (ES), 41\% e 33\% respectivamente, seguido pelos públicos de Ensino Técnico em nível médio (ET), Educação de Jovens e Adultos (EJA) e Ensino Fundamental (EF).

O Ensino Médio e o Ensino Superior também foram os níveis de ensino mais abordados nas pesquisas CTS, de acordo com o trabalho de revisão bibliográfica de Castro et al. (2019). Este dado também é evidenciado na pesquisa de Freitas e Ghedin (2015), que apontam a Educação Básica e os professores como sujeitos mais investigados.

A modalidade de ensino EJA (Figura 2) apresenta quantidade de publicações pouco expressiva comparada aos demais públicos. Esse público corresponde a apenas $4 \%$ dos trabalhos empíricos selecionados, sendo que só foram selecionados trabalhos que abrangem o público da EJA nas edições de 2011 e 2017. O mesmo acontece com as publicações que envolvem estudantes do Ensino Fundamental, somente 2\%, sendo que apenas na edição de 2019 foram encontradas pesquisas com esse público. Isso pode ser atribuído ao fato de que o Ensino de Química, por ser estruturado com conceitos e linguagens específicas, está mais presente no Ensino Médio, o que justifica também a maioria das publicações serem direcionadas para esse público.

A baixa quantidade de trabalhos com públicos da EJA e do EF indica necessária reflexão sobre cursos de formação inicial e de formação continuada de professores que atuam em ambas as modalidades de ensino, para que a abordagem CTS seja mais divulgada nesses cursos, evitando assim lacunas na formação, contribuindo para formação de professores mais críticos e atuantes que em suas práxis contribuem para que a escola exerça de fato sua função social. Outra reflexão pertinente é sobre os currículos escolares em ambas as modalidades de ensino, a EJA e o EF, cujos conteúdos podem ser articulados de maneira interdisciplinar, por meio de um ensino contextualizado com vistas à formação cidadã. 


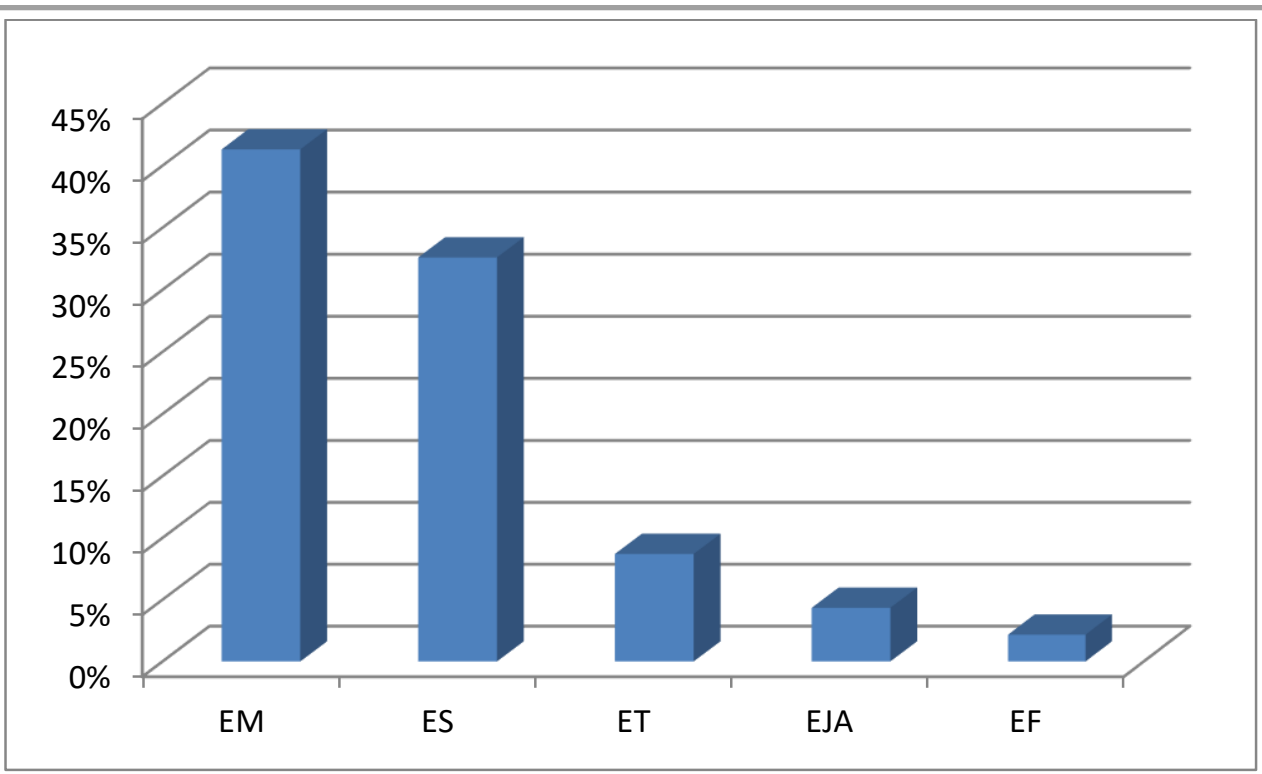

Figura 2 - Público alvo das pesquisas CTS.

Fonte: os autores

\section{Categoria - Temas Sociais Geradores}

$\mathrm{Na}$ análise desta categoria, percebe-se o quanto a abordagem CTS propicia a riqueza de diversidade de temas geradores, dos quais destacamos: lixo, combustíveis, fontes de energia, água, resíduos eletrônicos, entre outros. A maioria dos trabalhos empíricos analisados parte de um tema gerador ou de uma problemática, desenvolvida em uma abordagem CTS/CTSA, com foco na aprendizagem de conceitos químicos. Sobre os "temas sociais", Santos e Schnetzler (2003) afirmam que:

Os temas químicos sociais desempenham papel fundamental no ensino de química para formar o cidadão, pois propiciam a contextualização do conteúdo químico com o cotidiano do aluno, além de permitirem o desenvolvimento das habilidades básicas relativas à cidadania, como a participação e a capacidade de tomada de decisão, pois trazem para a sala de aula discussões de aspectos sociais relevantes, que exigem dos alunos posicionamento crítico quanto a sua solução (SANTOS e SCHNETZLER, 2003, p. 105).

A articulação de conhecimentos por meio de "temas sociais geradores" é uma estratégia de ensino relevante, pois as discussões pautadas nos temas geradores aproximam os estudantes dos conceitos da disciplina de química. No entanto, verifica-se que a abordagem de temais sociais, em alguns trabalhos analisados, contempla apenas os conteúdos tradicionais do currículo escolar e não engloba estratégias interdisciplinares, contrário àquilo que a abordagem CTS preconiza. É evidente que a construção do conhecimento por meio de temas sociais geradores tem sido benéfica para o Ensino de Química, mas é necessária a inserção do tema social gerador elencado nas outras disciplinas do conhecimento, como filosofia, sociologia, história, matemática, política, artes, manifestações culturais, entre outras. Essa pluralidade permite que os estudantes e professores possam refletir sobre o tema gerador por diversos ângulos e com isso a aprendizagem se torna mais significativa. 
A relevância de temas sociais e a interdisciplinaridade são discutidos no trabalho de revisão de Sousa et al. (2019), cujos autores descrevem duas perspectivas sobre as particularidades da inserção da abordagem CTS/CTSA no Ensino de Química; a primeira é a educação para cidadania e a segunda é a educação CTS, uma educação problematizadora pautada em temas sociais. Os autores apontam que essas duas perspectivas possibilitam o desenvolvimento de um ensino contextualizado em que a interdisciplinaridade é utilizada como alternativa para romper com um currículo tradicional praticado no Ensino de Ciências.

\section{Categoria - Referenciais Teóricos}

Esta categoria busca identificar os principais autores e obras utilizados como referenciais teóricos que fundamentam as pesquisas realizadas nos trabalhos analisados. Na Figura 3 são apresentados os números de citações dos principais autores sobre abordagem CTS referenciados nos 46 trabalhos analisados.

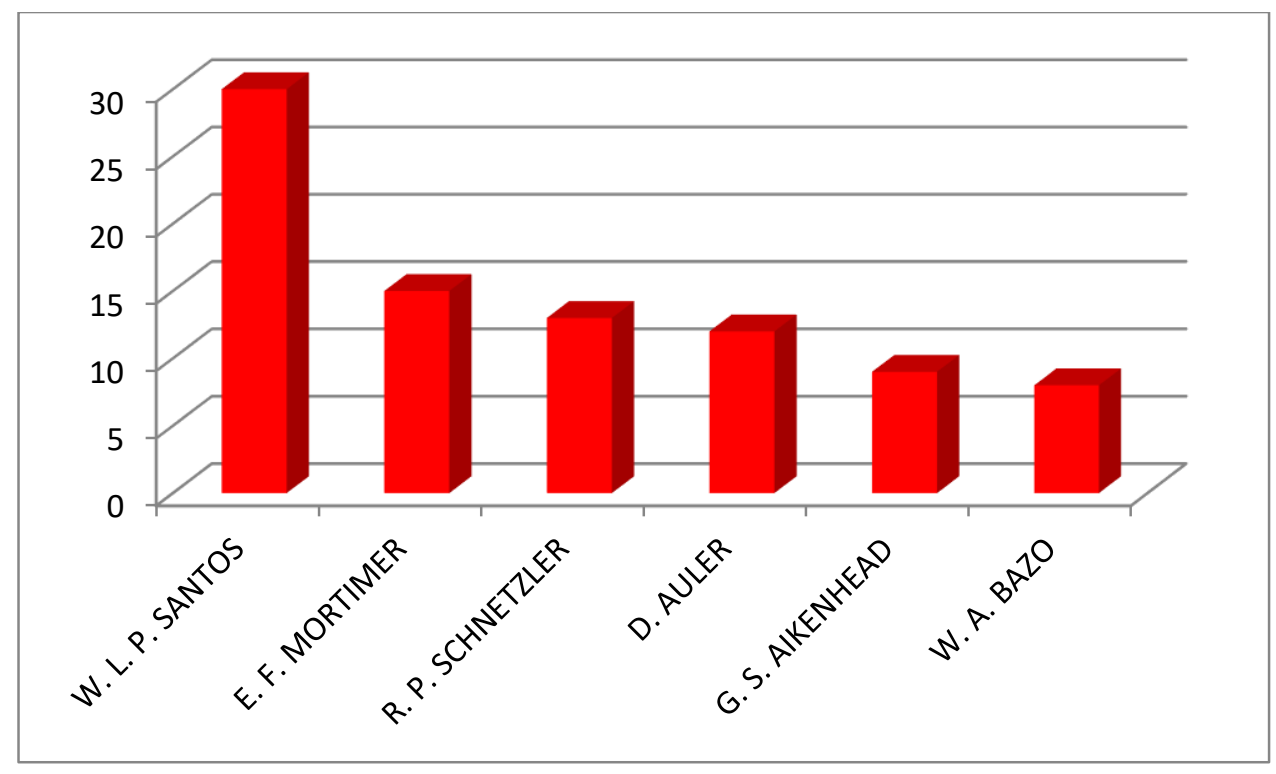

Figura 3 - Principais autores citados nos artigos analisados.

Fonte: os autores

Conforme podemos analisar na Figura 3, o autor brasileiro Wildson L. P. Santos foi o mais citado, pois $65 \%$ dos artigos analisados utilizaram suas publicações para fundamentar a discussão sobre CTS/CTSA. Nos trabalhos de revisão bibliográfica, Wilson L. P. Santos aparece como um dos principais referenciais teóricos citados nas produções analisadas (FREITAS; GHEDIN, 2015, BOUZON et al., 2018, CASTRO et al., 2019). Os trabalhos de Wildson Santos com esta abordagem, além de terem grande relevância, ajudaram a difundir a CTS pelo Brasil, levando esse autor a ser considerado um dos expoentes sobre CTS nas pesquisas brasileiras.

Na sequência, aparecem como autores mais citados: Eduardo F. Mortimer, Roseli P. Schnetzler, Décio Auler, Glen S. Aikenhead e Walter A. Bazzo. As obras mais citadas dos respectivos autores estão relacionadas no Quadro 3. 


\begin{tabular}{|l|l|}
\hline \multicolumn{2}{l}{ Quadro 3-Obras mais citadas. } \\
\hline Autores & \multicolumn{1}{c}{ Obras } \\
\hline Wildson L. P. Santos & $\begin{array}{l}\text { Contextualização no Ensino de Ciências por Meio de Temas CTS } \\
\text { em uma Perspectiva Crítica. Ciência \& Ensino, v. 1, número } \\
\text { especial, novembro 2007. }\end{array}$ \\
\hline $\begin{array}{l}\text { Wildson L. P. Santos e } \\
\text { Eduardo F. Mortimer }\end{array}$ & $\begin{array}{l}\text { Uma análise dos pressupostos teóricos da abordagem C-T-S } \\
\text { (Ciência-Tecnologia-Sociedade) no contexto da educação } \\
\text { brasileira. Ensaio - Pesquisa em Educação em Ciências, v. 2, n. 2, } \\
\text { p. 1-23, 2002. }\end{array}$ \\
\hline Décio Auler & $\begin{array}{l}\text { Enfoque Ciência-Tecnologia-Sociedade: Pressupostos para o } \\
\text { contexto brasileiro. Ciência \& Ensino, v. 1, número especial, } \\
\text { novembro 2007. }\end{array}$ \\
\hline $\begin{array}{l}\text { Wildson L. P. Santos e } \\
\text { Roseli P. Schnetzler }\end{array}$ & $\begin{array}{l}\text { Educação em Química: Compromisso com a cidadania. 3a ed. ljuí: } \\
\text { Editora Unijuí, 2003. }\end{array}$ \\
\hline Glen S. Aikenhead & $\begin{array}{l}\text { Educação Científica para todos. Tradução de Maria Teresa } \\
\text { Oliveira. 1a ed. Mangualde, Portugal: Edições Pedagogo, 2009. }\end{array}$ \\
\hline Walter A. Bazzo & $\begin{array}{l}\text { Ciência, tecnologia e sociedade: e o contexto da educação } \\
\text { tecnológica. 3a ed. Florianópolis: Editora UFSC, 2011. }\end{array}$ \\
\hline Wildson L. P. Santos e & $\begin{array}{l}\text { CTS e educação científica. Desafios, tendências e resultados de } \\
\text { pesquisa. Brasília: Editora UnB, 2011 }\end{array}$ \\
\hline Décio Auler
\end{tabular}

Fonte: os autores

Percebe-se que dos seis autores mais citados, cinco são autores brasileiros; o baixo número de autores estrangeiros nas citações das pesquisas brasileiras com enfoque CTS/CTSA, segundo Chrispino et al. (2013), pode estar relacionado às próprias limitações em relação ao idioma estrangeiro, ou seja, nem todos os pesquisadores no decorrer de sua trajetória escolar e/ou acadêmica tiveram a possibilidade de desenvolver essa competência. Outro fato que pode estar relacionado é a inexistência de obras estrangeiras desta temática nas bibliotecas de instituições de ensino ou da indisponibilidade destas obras em meio digital, dificultando a consulta de fontes primárias.

\section{Considerações Finais}

Este trabalho de revisão bibliográfica trouxe um panorama dos artigos sobre a abordagem CTS no Ensino de Química publicados nas atas do ENPEC das edições de 2011 a 2019. Tendo em vista que o ENPEC é um importante evento que reúne pesquisadores de diferentes instituições e regiões do Brasil, o mesmo reflete o perfil das pesquisas que estão sendo desenvolvidas por todo o nosso país. Nesse sentido, este trabalho possibilita uma reflexão sobre o uso da abordagem CTS no contexto brasileiro, sobretudo na educação básica, além de destacar a inserção de temas CTS nos diferentes níveis de ensino.

Os resultados quantitativos trazem um número significativo de publicações realizadas no ENPEC, principalmente no ano de 2017; entretanto, a tendência de aumento ainda é pequena, 
visto que o ENPEC é um dos principais eventos científicos da área de Educação em Ciência. Outro dado preocupante é o número inexpressivo de publicações na modalidade de ensino EJA, assim como para o ensino fundamental.

Destacamos a diversidade de temas sociais geradores na abordagem CTS, porém em determinados trabalhos os temas não são abordados de maneira interdisciplinar, sendo esta uma das propostas da CTS. A interdisciplinaridade se faz necessária e é uma estratégia eficaz para romper com o currículo tradicional e assim minimizar possíveis lacunas que possam ocorrer nos processos de ensino e de aprendizagem. Tais aspectos são essenciais para que a construção do conhecimento em sala de aula seja significativa tanto para os alunos quanto para o professor.

A análise indica que o autor Wildson L. P. dos Santos é o principal referencial teórico citado pelos autores dos 46 trabalhos analisados, com destaque para o artigo "Contextualização no Ensino de Ciências por Meio de Temas CTS em uma Perspectiva Crítica", publicado em 2007 e o livro "Educação em Química: Compromisso com a Cidadania", publicado em parceria com Roseli P. Schnetzler, em 2003.

Os resultados obtidos mostram a relevância da inserção da abordagem CTS na prática docente, em seus diferentes níveis de ensino e estreitar o distanciamento dessas abordagens nos espaços escolares. A discussão sobre CTS durante os cursos de formação inicial e continuada de professores, assim como o incentivo ao desenvolvimento e divulgação de pesquisas relacionadas a esta abordagem, podem ser ferramentas essenciais para trazer mudanças na práxis de muitos docentes, o que consequentemente proporcionará mudanças significativas na Educação Brasileira.

\section{Referências}

BARDIN, L. Análise de Conteúdo. São Paulo: Edições 70, 2011.

BOUZON, J.; BRANDÃO, J.; SANTOS, T.; CHRISPINO, A. O Ensino de Química no ensino CTS Brasileiro: uma revisão bibliográfica de publicação em periódicos. Química Nova na Escola, v. 40, n. 3, p. 214-225, 2018.

BRASIL. Base Nacional Comum Curricular. Brasília: MEC, 2017. Disponível em: <http://basenacionalcomum.mec.gov.br/images/BNCC_El_EF_110518_versaofinal_site.pdf.> Acesso em 11 out. 2021.

BRASIL/MEC. Lei no. 9.394, de 20 de dezembro de 1996. Lei de Diretrizes e Bases da Educação Nacional. Brasília, DF: 20 de dezembro de 1996. Disponível em: <http://portal.mec.gov.br/seesp/arquivos/pdf/lei9394_ldbn1.pdf>. Acesso em 11 out. 2021.

BRASIL/MEC. Parâmetros Curriculares Nacionais para o Ensino Médio; Parte III: Ciências da Natureza, Matemática e suas Tecnologias. Brasília: MEC/SEMTEC, 2000. Disponível em: <http://portal.mec.gov.br/seb/arquivos/pdf/ciencian.pdf>. Acesso em 11 out. 2021.

CASTRO, M. C.; LIU, A. S.; MIRANDA Jr, P. Abordagem CTS: Uma análise dos anais dos Encontros Nacionais de Ensino de Química, de 2012 a 2018. Rev. Ciênc. \& Ideias, v. 10, n. 3, p. 191-205, 2019. 
CHRISPINO, A; ALBUquerque, M. B.; FReITAS, A. C. C.; SILVA, M. A. F. B. A área CTS no Brasil vista como rede social: Onde aprendemos? Ciênc. Educ., Bauru, v.19, n.2, p. 455-479, 2013.

DEMO, P. Metodologia do conhecimento científico. São Paulo: Atlas, 2000.

FREITAS, L. M.; GHEDIN, E. Pesquisas sobre Estado da Arte em CTS: Análise Comparativa com a Produção em Periódicos Nacionais. Alexandria Revista de Educação em Ciência e Tecnologia, v. 8, n. 3, p. 3-25, 2015.

GIL, A. C. Como elaborar projetos de pesquisa. $6^{\text {a }}$ ed, São Paulo: Atlas, 2017.

LOCATELLI, A.; ZOCH, A. N.; AMARAL, L. C. Z. Enfoque CTS no Ensino de Química: uma pesquisa do "estado da arte". ENCITEC - Ensino de Ciências e Tecnologia em Revista, v. 5, n. 1, p. 34-47, 2015.

LUCA, A. G. O Ensino de Química e algumas considerações. Revista Linhas, v. 2, n.1, p. 1-10, 2001.

OLIVEIRA, C. S.; SALGADO, T. D. M. Contextualizando conceitos de reutilização e reciclagem como motivação para compreensão da ciência no âmbito social na Educação de Jovens e Adultos. In: Anais do XI ENCONTRO NACIONAL DE PESQUISA EM EDUÇÃo EM CIÊNCIAS, Florianópolis (SC), 2017.

PIZZATO, M. C. Ciência, Tecnologia, Sociedade e Ambiente. In: SCHWANKE, C. (Org.). Ambiente: Conhecimentos e Práticas. Porto Alegre: Bookman, p. 1-14, 2013.

SANTOS, W. L. P; SCHNETZLER, R. P. Educação em química - Compromisso com a cidadania. 3ạ ed. ljuí: Editora Unijuí, 2003.

SANTOS, W. L. P.; GALIAZZI, M. C.; JUNIOR, E. M. P.; SOUZA, M. L.; PORTUGAL, S. O enfoque CTS e a Educação Ambiental: possibilidades de "ambientalização" da sala de aula de Ciências. In: MALDANER, O. A.; MACHADO, P. F. L.; SANTOS, W. L. P. (Org.). Ensino de Química em foco. ljuí: Editora Unijuí, p. 131-157, 2010.

SANTOS, W. L. P.; MORTIMER, E. F.; Uma análise dos pressupostos teóricos da abordagem C-T$S$ (Ciência-Tecnologia-Sociedade) no contexto da educação brasileira. Ensaio - Pesquisa em Educação em Ciências, v. 2, n. 2, p. 1-23, 2002.

SCHNETZLER, R.; ARAGÃO, R. M. R.; Importância, Sentido e Contribuições de Pesquisa para o Ensino de Química. Química Nova na Escola, n.1, maio, p.27-31, 1995.

SOUSA, B. L. S.; BEZERRA, C. W. B.; SILVA, J. R. S.; CATANHEDE, S. C. S.; CATANHEDE, L. B. Cenário das publicações CTS/CTSA no ensino de química: revisão bibliográfica de publicações no portal de periódicos da CAPES/CAFÉ. Braz. J. of Develop., Curitiba, v. 5, n. 11, p. 17267-27283, 2019.

SOUZA, A.C. N.; MESQUITA, D. W. O.; FARIAS, S. A.; Reflexões e desafios acerca da abordagem Ciência, Tecnologia, Sociedade e Ambiente na Educação em Ciências/Química na formação do cidadão. In: Anais do X ENCONTRO NACIONAL DE PESQUISA EM EDUÇÃO EM CIÊNCIAS, Águas de Lindóia (SP), 2015.

STRIEDER, R. B.; KAWAMURA, M. R. D. Educação CTS: Parâmetros e Propósitos Brasileiros. Alexandria Revista de Educação em Ciência e Tecnologia, v. 10, n. 1, p. 27-56, 2017. 